\title{
ENTREVISTA COM JACYNTHO LINS BRANDÃO ${ }^{1}$
}

O SENHOR UTILIZA O TERMO ROMANCE PARA FALAR DE ALGUNS TEXTOS LITERÁRIOS GREGOS, COMO, POR EXEMPLO, AS EFESÍACAS, DE XENOFONTE DE ÉFESO E AS ETIÓPICAS, DE HELIODORO. NESTA LINHA DE RACIOCÍNIO, O GÊNERO ROMANCE NÃO É PRÓPRIO DA MODERNIDADE, MAS TEVE SEU FLORESCIMENTO NO PERÍODO CHAMADO “RENASCIMENTO GREGO"?

Em termos históricos, dizer que o romance é da Modernidade (ou mesmo como a "epopeia da Modernidade") no sentido de que só então foi inventado, não é exato. Mas, de fato, só a partir do século XVII se efetivou o reconhecimento do gênero e - o que não deve ser menosprezado - sua nomeação como roman/romance (termo que do francês foi emprestado a outras línguas, como o português, italiano e o

russo) ou novela/novel (que o espanhol e o inglês buscaram no italiano novella, em que ele nomeava uma narrativa curta, como em português). Esse reconhecimento tem uma data inicial precisa: 1670, quando aparece o prefácio de PierreDaniel Huet, bispo de Abranches, ao romance Zaïde, de Jean Regnaut, Monsieur de Segrais (secretário de Madame de Lafaiette, considerada hoje em dia a verdadeira autora), prefácio que se apresenta como uma carta de M. Huet a M. de Segrais, com o subtítulo: De l'origine des romans. Ora, o texto de Huet logo passou a ser publicado independentemente - com o título Traité de l'origine des romans - e teve muita repercussão (apenas dois anos depois de seu surgimento em

1. Professor titular de Língua e Literatura Grega na Faculdade de Letras - UFMG. 
francês, ou seja, em 1672 , já era publicado em inglês, $A$ treatise of romances and their original, aparecendo dez anos depois a versão para o alemão). O que se constata no estudo de Huet é que o reconhecimento do gênero se faz por retrospectiva, isto é, a partir da forma do romance naquele momento, em especial de Zaïde, elogiado por sua perfeição, Huet retrocede até as origens antigas desse tipo de narrativa, postulando inclusive uns antecedentes orientais, mas tendo como dados concretos apenas os romances gregos e latinos dos primeiros séculos depois de Cristo. Assim, o reconhecimento moderno do gênero se faz ao mesmo tempo em que se reconhece que ele é antigo, constituindo-se para ele uma história, o que, aliás, é o objetivo de Huet, tratar da "origem" do romance. Antes desse "batizado", essas narrativas de ficção em prosa recebiam denominações variadas, como, em grego, lógos e plásma, em latim novella - sendo de destacar o termo seiscentista "epopeia em prosa" (estudado por Adma Muhana), que toma como modelo justamente As etiópicas de Heliodoro, ou seja, um romance grego do terceiro século. Aliás, Heliodoro exerceu uma influência muito grande no romance moderno: Cervantes declara que ele é o modelo com o qual disputa em Os trabalhos de Persiles e Segismunda, que ele, Cervantes, considerava ser sua obra prima.

Agora um dado bastante importante: acredito que é justamente porque o romance é um gênero por natureza elusivo
- talvez por ser muito experimental, ou, na terminologia de Kristeva, "transformacional" - que a temporalidade se torna para ele tão impactante, mais impactante que em outros gêneros mais codificados. É como se, a cada obra, ele fosse reinventado. Então, a vinculação com vários regimes de temporalidade é muito destacada. Daí a impressão, que não deixa de ter um tanto de autêntica, de que ele foi reinventado na Modernidade.

A SEU VER, QUAL A RELACCÃO ENTRE O ROMANCE PÓS-ANTIGO COM O ROMANCE CONTEMPORÂNEO? E COMO O SENHOR PERCEBE A MÍMESIS EM CADA UM?

Em 1998, quando se completavam os 500 anos da primeira edição impressa de Dáfnis e Cloé de Longo (texto do segundo século d. C.), a Biblioteca Britânica organizou uma exposição dos volumes que possuía dessa obra, em grego ou em traduções. Eram mais de 500, o que mostra que se trata de um autêntico best seller, com em média uma edição por ano durante meio milênio. Mais que isso, a tradução que dele fez Amyot, no século XVI, tornou-se ela própria um clássico da língua francesa, servindo de base para a tradução elizabetana para o inglês. Com isso quero exemplificar como o romance antigo nunca deixou de ser lido, dialogando, direta ou indiretamente, com o romance de outras épocas. Mas quero também ressaltar a importância que têm as traduções na difusão do romance, um gênero do qual se poderia dizer 
que é recebido mais através de traduções que nas línguas originais. A poesia é mais difícil de traduzir e de ser recebida em tradução, enquanto a ficção em prosa se mostra mais apta para isso, noutros termos, a prosa pode com mais facilidade manter seus efeitos ao ser traduzida que o texto em versos. Acredito que isso acontece no caso do romance porque o que ele mimetiza é justamente um discurso não-estilizado (ou não-literário) - como declaradamente é o poético -, em algum grau disputando com o coloquial. Não se me entenda mal: não quero com isso dizer que a linguagem do romance seja coloquial, mas apenas que, ao recusar a linguagem ritmada (ou musical) da poesia e optar pela prosa ele realiza um tipo de mimese que, em princípio, parece negar-se enquanto tal - isso configurando um nível máximo de estilização. Provavelmente é isso que não só torna possível como induz a todo tipo de experimentalismos, até mesmo à exploração de uma prosa ritmada (como no próprio Dáfnis e Cloé ou em Iracema de José de Alencar).

Voltando à questão temporal: o multilinguismo do romance, decorrente de sua traduzibilidade, leva à constituição de ciclos que se podem reconhecer ao longo da história. Isso é muito claro para o romance medieval, por exemplo. Qual o original de Tristão e Isolda ou de outras obras do ciclo arturiano? Depois da constituição dos entrechos no âmbito da oralidade, em que as narrativas em geral se fazem em verso, abre-se um leque de versões em diferentes línguas que, cada qual por seu turno, recriam a história. Alguns comentadores entendem que, durante a Idade Média, na passagem das formas épicas (em verso) para as romanceadas (em prosa) há um influxo do romance antigo, em que a história de amor dos protagonistas recebe um tratamento "biográfico" e o seu papel se torna simétrico (isso se diz nomeadamente a propósito de Tristão e Isolda). Podemos pensar também nesses ciclos para situações mais recentes: o romance barroco ou preciosista apresenta-se assim; o romance do século XIX também: O crime do Padre Amaro de Eça de Queiroz e La faute de l'Abbé Mouret de Zola são publicados no mesmo ano de 1875. Então, os adjetivos ganham um grande peso: romance antigo, romance de cavalaria, romance realista, nouveau roman etc. As formas que o romance adquire em diferentes temporalidades dialogam com o conjunto do gênero, ou seja, mesmo que alguns textos antigos sejam, hoje, menos conhecidos (embora eu diria que são agora mais conhecidos que no século passado), como acontece com As etiópicas, cujo papel nos séculos XVI e XVII já salientei, outros fazem parte do arsenal de um leitor comum de romances, como Dáfnis e Cloé ou o Satíricon de Petrônio. Isso para não falar nos breves romances paródicos de Luciano, Lúcio ou o asno e Narrativas verdadeiras. 
QUAL A IMPORTÂNCIA DOS ESTUDOS DA POIESIS E TEKKHNE PARA A CRÍTICA LITERÁRIA?

Esses são conceitos que se tornaram basilares para a teorização sobre a literatura que teve início na Grécia. Acredito que sua funcionalidade se deve ao fato de que os textos entendidos como "poéticos" - o que para Aristóteles implica dizer que são miméticos, não se restringindo aos metrificados - partem do pressuposto de que são uma forma de pseûdos, ou seja, nos nossos termos, de ficção. É esse caráter ficcional que os torna complexos do ponto de vista não tanto da produção, mas especialmente da recepção. Um discurso que se pretende verdadeiro, o que quer dizer que se apresenta ao recebedor como verdadeiro, não tem necessidade de justificar-se, pois baseia-se nesse argumento externo, a verdade, garantida por uma autoridade, como um deus, um rei ou um sábio, por exemplo. Já quando ingressamos na esfera do poético, que não se entende como antípoda da verdade, mas como um tipo de discurso que precede à oposição verdadeiro/falso, as coisas se tornam mais complexas. Que valor social atribuir a um gênero de discurso que, para ser eficaz, exige que seu recebedor saiba que ele não é verdadeiro? É o que se expressa na famosa resposta de Simônides a alguém que lhe perguntou por que sua poesia não surtia efeito entre os tessálios, ele tendo respondido que a razão era que eles, os tessálios, eram muito estúpidos para se deixarem enganar por ele. Nesse jogo que, ressalte-se, envolve menos o poeta que seu público, uma percepção da linguagem que poderíamos chamar de ingênua dá lugar a uma concepção sofisticada, que impõe a teorização. A primeira solução, podemos dizer que na sequência do que afirmam as Musas na Teogonia de Hesíodo ("sabemos dizer muitos pseúdea semelhantes a coisas autênticas/ e sabemos, quando queremos, proferir verdades"), é dada por Platão: há o lógos verdadeiro e o pseûdos, mas o mito (transmitido pelos poetas, logo, a poesia) é uma terceira espécie do lógos, um pseûdos no todo em que há também algo de verdadeiro. Esse algo de verdadeiro, num primeiro nível, tem relação com o semelhante (os deuses representados pelo poeta devem ser semelhantes ao que deve ser um deus), mas não creio que podemos reduzi-lo só ao verossímil, como geralmente se entende, enquanto algo semelhante ao verdadeiro. O termo utilizado por Aristóteles, eikós, significa semelhante, mas sem restringir a quê. Entendido como 'provável', 'razoável', abriria nossa perspectiva para considerar que se trata antes de um traço interno ao discurso que uma relação com algo exterior, embora não fosse razoável que Aristóteles pensasse que a probabilidade e razoabilidade do poético pudesse ser contrária à natureza, pois também o poético é parte dela. Então, algo como um centauro é eikós, mesmo sem o referencia externo, porque se trata de algo que "poderia acontecer" (ou poderia existir), conforme a famosa distinção que ele estabelece entre a poesia e a história (esta última tratando do que 
“aconteceu”). Por que um centauro é eikós? Por que, mesmo sendo uma figura compósita, guarda sua coerência - o que em termos do entrecho ele chama de "necessidade".

Da forma como entendo e num sentido bastante geral o desenvolvimento de toda a teorização grega sobre a mimese busca responder a esse problema que a poesia como pseûdos levanta, o qual, ainda que possa parecer hoje banal, é bastante grave. Trata-se, então, de um problema da esfera da recepção, vale dizer, na esfera do conjunto de gêneros de discurso com que lida uma cultura, de prover as bases para um controle social da recepção. No caso grego - e, por consequência, pode-se dizer que do que chamamos de literatura ocidental - a chave para isso foi achada na poética, no sentido da carpintaria do texto, isto é, a apreciação crítica depende de perceber os elementos de composição do texto ou de como se faz nele a mimese. Esse é um aspecto eminentemente ligado à tékhne, a aproximação com outros poetas, como o oleiro, por exemplo, podendo ser esclarecedora: em primeiro lugar, o valor de um vaso está em seu uso - e ele não deve deixar que o líquido vaze, por exemplo; mas se a isso se acrescenta uma pintura ou uma inscrição, ele deixa de ter um sentido meramente utilitário para ganhar um valor dado pela perícia (a tékhne) com que foi fabricado (sua póesis). Mais ainda se dirá no caso de o pintor ter pintado o vaso, eliminando o valor utilitário e transportando-o então inteiramente para a esfera mimética, vale dizer, do psê̂dos, em que o valor que permanece é não mais que o poiético. Costumo fazer um contraponto entre essa experiência grega e a hebraica: não tem sentido falar de poesia na Bíblia porque o valor do texto, da perspectiva do Israel antigo, está todo posto na verdade. Então, o que o judaísmo desenvolveu foi uma rica hermenêutica, pois esse é o único recurso para que o fiel se ponha em relação com um texto em tal grau verdadeiro. No caso grego, o recurso para o estabelecimento dessa relação, que também, naturalmente, implica num controle social da recepção, foi o desenvolvimento de poéticas, vale dizer, de teorizações sobre poesia, as quais, não por acaso, não foram obra dos próprios poetas, mas sim dos filósofos.

PODE-SE DIZER QUE A FILOSOFIA MODERNA INTENSIFICOU, SOBRETUDO APÓS KANT, O INTERESSE PELA OBRA DE ARTE, PRINCIPALMENTE PELA LITERATURA. COMO O SENHOR CONCEBE ESTA RELAÇÃO?

Pelo que eu acabo de dizer se pode perceber que a filosofia sempre se interessou pela obra de arte. Eu diria que a arte, como outros problemas, como a verdade e a justiça, a arte enquanto problema atravessa toda a história da filosofia. Trata-se de uma esfera que não se pode ignorar, não só pelo papel que lhe cabe, como pelas indagações que levanta. Evidentemente a cada etapa novas perguntas são formuladas e novas respostas ensaiadas. O que acho que há 
de novo depois de Kant é uma certa autonomia que a estética, enquanto uma das disciplinas filosóficas, adquire. Como eu disse antes, o pensamento sobre a arte não se separa, em Aristóteles, por exemplo, da física, da ética ou da política. $\mathrm{O}$ caso de Platão é exemplar: a distinção da poesia em espécies diegéticas (diegese simples, diegese mimética, diegese mista) encontra-se na República, um diálogo cujo tema é a justiça, o viés sendo político. Essa tendência pós-kantiana responde a uma autonomização da própria arte, que começa a configurar-se a partir do século XVI mas só se impõe mesmo no século XIX.

TENDO EM VISTA O SEU INTERESSE SOBRE A POLÍTICA E A CULTU RA BRASILEIRA, GOSTARIA QUE O SENHOR COMENTASSE SOBRE AS MANIFESTAÇÕES OCORRIDAS NO BRASIL NO MÊS DE JUNHO AINDA SOBRE ESTE PONTO, O SENHOR VE ALGUM PROCESSO ARTíSTICO CAPAZ DE REPRESENTAR ESTETICAMENTE ESTE TIPO DE EVENTO?

Acho que o aspecto principal das manifestações foi o sentimento de indignação, que permitia que cada qual pudesse aparecer com sua pauta (li numa revista que em Porto Alegre havia alguém com um cartaz "pela volta da tomad de dois pinos"!), podendo-se dizer que houve mesmo um certo consenso em torno dessa interpretação. Mas o outro ponto forte, no meu ponto de vista, foi a organização (que muita gente achou que não havia) ter sido puxada por gente muito jovem, capaz de experimentar formas novas de arrebanhar pessoas e de se manifestar. Quem criticou o espontaneísmo do movimento se esqueceu - ou quis ignorar intencionalmente - que a insatisfação estava em gestação há algum tempo, tendo eclodido com o aumento das passagens de ônibus, puxadas pelos movimentos que reivindicam tarifa zero, meia para estudantes etc. Aqui em Belo Horizonte foi um pouco diferente, porque o aumento já havia acontecido em janeiro, então ficou mais claro o papel do Comitê dos Atingidos pela Copa, misturado com a turma da Praia da Estação, Fora Lacerda, Ocupe a Câmara, movimentos em atividade nos últimos três anos. Os governos (em todos os níveis) vinham fazendo vista grossa para movimentos como esses pura e simplesmente porque os governantes no Brasil são extremamente autocráticos (com raríssimas exceções). Por exemplo, que só depois das manifestações o Governador de Minas tenha recebido o pessoal que vivia do trabalho nas barraquinhas em volta do Mineirão, pessoal que foi alijado de lá desde que a reforma do estádio começou e, terminada a reforma, foi proibido de voltar, revela um grau extremo de insensibilidade e falta de educação política. Então foi bom ver esse tipo de arrogância, em vários níveis do executivo e legislativo, quebrado por obra e graça das manifestações. Que eles, os políticos de plantão, voltem imediatamente ao modo como agiam antes (como sempre agiram), o que também se constatou, fica por conta do demérito que é próprio 
deles. Seria bom se houvesse resultados imediatos. Mas seria ingenuidade esperá-los com facilidade. O mais importante, no meu ponto de vista, é que a população, ao manifestar-se, provou que tem dignidade.

$\mathrm{Eu}$ acredito muito nas mudanças que se fazem homeopaticamente, porque em geral são aquisições para sempre. Não está longe o tempo em que havia uma grande parte da população que achava que manifestações públicas eram coisa de vagabundos, de arruaceiros, de comunistas etc. Observar o quanto isso mudou é importante. Quantas vezes eu tive antes de contra-argumentar diante de alguém que reclamava do transtorno que, naturalmente, qualquer manifestação pública provoca, que em Paris tem praticamente uma por dia - o exemplo era intencionalmente maldoso, já que os que reclamavam em geral pensavam que isso era coisa de gente atrasada e no primeiro mundo não acontecia. Achei cômico como principalmente a imprensa televisiva teve de botar a viola no saco mudando o bordão costumeiro de que é um absurdo atrapalhar a vida das pessoas com passeatas e assemelhados, elegendo então como válvula de escape concentrar-se nos "vândalos" (em termos de análise do discurso, ouvir os repórteres dizendo "ali está um vândalo fazendo ta coisa" era simplesmente cômico). Essa necessidade de estigmatizar um lado (os "ordeiros" versus os "vândalos") desvia a atenção do fato de que a quebradeira teve um significado importante. É que, na minha interpretação, o ponto mais básico da indignação manifestada de modo tão variado está em que - não só no Brasil, como no mundo - a política foi reduzida a economia. E no reino da economia tudo é inevitável. As manifestações foram então uma irrupção da política. O que disse o líder do Movimento Passe Livre ao Prefeito de São Paulo, quando este o chamou para uma reunião e mostrou os números para justificar por que não podia revogar o aumento das passagens, foi lapidar: você é que é o governante e é quem deve buscar a solução. Afinal, a política existe para isso, para construir possibilidades. Inclusive porque o argumento econômico é usado bastante como uma espécie de chantagem para esconder a falta de vontade e competência política.

Do ponto de vista de como processos artísticos poderiam representar esses eventos, acho que de um modo semelhante ao que eles foram: uma unidade baseada não em uma liderança, mas numa liberdade de expressão levada ao extremo. Uma das coisas que de mais interessante, por exemplo, acho que apareceu é a chamada "assembleia horizontal". Isso de um conjunto de pessoas tirar decisões sem lideranças e por consenso é alguma coisa que me deixa estranhado - a partir da minha experiência de assembleias, com toda aquela organização tradicional: presidente, pauta, deliberação da maioria etc. - mas ao mesmo tempo extremamente estimulado 
ao pensar que o esgotamento que se verifica nas formas de representação e de deliberação tradicionais não é o fim do mundo porque outras experiências são possíveis. Sem querer sugerir nenhuma camisa-de-força, é provável que um movimento como as manifestações de junho requeresse algum processo de arte não só coletivo, como também horizontal. 